\title{
IMPACTOS DO CASO DO CANAL “NÃO FAMOSO” NA POLÍTICA DE GOVERNANÇA DO YOUTUBE NO BRASIL
}

\author{
Alexandre Ferreira de Assumpção Alves* \\ Priscilla Menezes da Silva**
}

\begin{abstract}
RESUMO: O acesso à internet de alta velocidade através de smartphones potencializa o poder das redes sociais, ambientadas em plataformas digitais de propriedade de sociedades estrangeiras e que operam em quase todos os países com políticas de governança bem uniformes. Através do método indutivo, pesquisa bibliográfica e documental e baseado em estudo de caso envolvendo o canal "Não Famoso" contra o Google, o artigo pretende examinar como uma decisão local, oriunda do Tribunal de Justiça de Santa Catarina, aparentemente teve o condão de alterar os Termos de Serviço do Youtube em vários países, sendo a mudança mais significativa no Brasil.
\end{abstract}

Palavras-chave: Governança; Internet; Direito Autoral; Termos de Serviço; YouTube.

\section{"NÃO FAMOSO" CHANNEL'S CASE IMPACT ON THE GOVERNANCE POLICY OF YOUTUBE IN BRAZIL}

\begin{abstract}
The access to high-speed internet available via smartphones maximizes social media's power based on digital platforms owned by foreign companies that operate almost worldwide using governance policies that are pretty much the same everywhere. Through the inductive method, bibliographic and documental research and based on the analysis of the case involving the "Não Famoso" channel v. Google this paper shall examine how a local decision from Santa Catarina State Court of Justice apparently brought changes to Youtube's Terms of Service in many countries, especially in Brazil.
\end{abstract}

Keywords: Governance; Internet; Copyright; Terms of Service; You Tube.

\footnotetext{
${ }^{*}$ Mestre e Doutor em Direito. Professor Associado nas Faculdades de Direito da UERJ e da UFRJ. Docente permanente do PPGD da UERJ; alexandreas@ direito.uerj.br

** Advogada e consultora nas áreas de Direito Empresarial, Inovação e Entretenimento; membro da Associação Internacional de Direito e Tecnologia (ITechLaw). Mestre em Direito Empresarial pela UERJ, cursando Doutorado; Professora da ESPM/RIO e do Curso Master; pmenezes.uff@gmail.com
} 


\section{INTRODUÇÃ̃o}

É indubitável a ocorrência de transformações nas relações sociais a nível mundial, em grande parte, motivadas pelo acelerado desenvolvimento tecnológico impactante também nas formas de comunicação virtual e nas mídias eletrônicas. Ocorre que mudanças profundas têm ocorrido em espaços de tempo cada vez menores, alterando significativamente o modo de ser e viver das pessoas. Hábitos de consumo, interações sociais, formas de aprendizado, relações laborais, estruturas empresariais, todos estes aspectos têm sido alterados com o advento da internet de alta velocidade (high speed internet) e todas as inovações proporcionadas por ela, em especial o acesso cada vez melhor a programas e aplicativos de entretenimento. Por outro lado, algumas alterações em decisões negociais e políticas de governança são determinadas pelo Direito, ou mesmo pontualmente por decisões judiciais dos Estados locais, sem embargo de o conteúdo ser gerado alhures.

O fenômeno do Youtube surgiu em 2005 e consagrou-se como uma rede social ${ }^{1} /$ plataforma de compartilhamento de vídeos caseiros. Em 2006, essa rede/plataforma foi adquirida pela Alphabet Incorporation e se tornou uma das subsidiárias da Google Limited Liability Company (Google LLC) ${ }^{2}$. Com o slogan "Broadcast Yourself", que pode ser traduzido livremente como transmita você mesmo ou você na telinha ${ }^{3}$, hoje o Youtube é o segundo website mais visitado no mundo, com uma média de 9 minutos diários de acesso por usuário, segundo levantamento realizado pela Alexa, da Amazon ${ }^{4}$.

Certamente tamanha acessibilidade gerou uma sistemática violação de direitos autorais em um momento no qual a internet já era de alta velocidade e os smartphones tornavam-se populares. Usuários postavam séries de TV inteiras, prática ilícita que a plataforma

\footnotetext{
${ }^{1}$ Em que pese a discussão sobre a natureza de rede social ou mídia social do Youtube, neste artigo entende-se que se trata de espécie de rede social, na medida em que conecta pessoas através das inscrições nos canais, com possibilidades de comentários e outras formas de interação entre os usuários, como as "curtidas” (likes) nos vídeos e compartilhamento de conteúdo.

2 A Google LLC é uma sociedade empresária sediada nos Estados Unidos da América, mas com atuação transnacional, que presta serviços virtuais (on line) e de desenvolvimento de programas de computador (software). O "Google", como é popularmente conhecido, hospeda e desenvolve uma série de serviços e produtos baseados na internet e uma de suas receitas principais é através da publicidade pelo AdWords (anúncios em forma de links encontrados, principalmente, nos mecanismos de pesquisa relacionados às palavras-chave que o internauta está pesquisando). A Google LLC, fundada em 1998 Larry Page e Sergey Brin, é a principal subsidiária da Alphabet Inc. No Brasil, a Google LLC atua através de sua subsidiária Google Brasil Internet Ltda.

${ }^{3}$ A palavra "tube" na língua inglesa também serve para se referir à televisão.

${ }^{4}$ Trata-se de uma inteligência artificial desenvolvida pela Alexa Internet Inc., subsidiária da Amazon.com, Inc.. Os aparelhos Amazon Echo e Echo Bot conectam-se ao serviço, que está apto a interagir com o usuário por meio de voz, reproduzir músicas, elaborar listas de tarefas, configurar alarmes, prover informações sobre tráfego, temperatura, entre outras funções, além de controlar sistemas e aparelhos inteligentes e conectados.
} 
minimizou limitando o tempo máximo dos vídeos a 10 minutos, restrição abandonada posteriormente. Na sequência à restrição, usuários passaram a postar vídeos fracionados (parte 1, 2 etc) para burlar a regra. Iniciou-se, destarte, uma verdadeira disputa entre Youtube e os usuários, a fim de preservar a integridade dos conteúdos postados.

A questão da tutela dos direitos autorais sempre foi uma temática importante para a rede social, que mantinha até maio de 2018 uma política de governança uniforme nos países em que atua. Não obstante, tal orientação foi alterada após o julgamento em segunda instância de dois processos envolvendo o Canal "Não Famoso" e o Google. Dentro desta mudança de paradigma, o presente artigo tem como objetivo geral demonstrar como decisões judiciais podem interferir em políticas de governança de redes sociais com sede fora do Brasil.

A fim de alcançar tal empreitada, tem-se como objetivos específicos: (i) analisar os acórdãos do Tribunal de Justiça do Estado de Santa Catarina relativos ao Canal "Não Famoso"; (ii) analisar a política de governança da rede social Youtube antes e depois do julgamento das apelações n. 0000447-46.2016.8.24.0175 e 0000412-86.2016.8.24.0175, ambas oriundas do referido Tribunal de Justiça e (iii) verificar o comportamento aparentemente sistemático do Google em evadir-se de jurisdições que não sejam a norte-americana, através do caso Equustek.

A metodologia da pesquisa adota o método indutivo, pois parte do estudo de casos específicos para formular uma proposição geral, com supedâneo em referências bibliográficas e documentais. Primeiramente, analisar-se-ão os processos supramencionados julgados pelo Tribunal de Justiça do Estado de Santa Catarina e, em um segundo momento, será traçado um comparativo entre os Termos de Serviço do Youtube aplicados no Brasil e em mais onze países após as decisões referidas. Por fim, pretende-se demonstrar através de análise de outro caso concreto (Equustek) o reiterado comportamento do Google para evadir-se de jurisdições estrangeiras.

\section{O CASO CANAL “NÃO FAMOSO” X GOOGLE}

A manutenção de Canais no Youtube se tornaram meio de vida e auferimento de ganhos para muitas pessoas, ou pelo menos de complemento de renda. É a situação de Daniel Cândido dos Santos, criador do Canal "Não Famoso", cuja maior parte de seu conteúdo se destina à paródias e seus vídeos são monetizados. Portanto, o criador do Canal exibe publicidade de terceiros e lucra com essa prática, de acordo com a quantidade de visualizações. Duas de suas

\footnotetext{
${ }^{5} \mathrm{O}$ acesso ao canal é feito pelo endereço: https://www.youtube.com/channel/UCyYxrTCHjqFiRLqLogKXb5w
} 
paródias foram objeto de disputa judicial: "10\%”, criada com base na música de mesmo título das cantoras Maiara e Maraísa e "Medonhamente", inspirada na música Malandramente, dos artistas Dennis DJ e Mc's Nandinho \& Nego Bam.

Quem representa os direitos autorais das obras nos dois casos citados na parágrafo anterior é a sociedade ONErpm Comércio e Serviços de Mídia Digital Ltda., que utilizou o procedimento do You Tube intitulado de "notice and take down"6 para tirar os vídeos do ar.

A Lei n. 9.610/98 - Lei dos Direitos Autorais (LDA) - tem natureza híbrida, pois está alicerçada nos direitos moral e patrimonial do autor, descritos, respectivamente, nos arts. 24 e 28. Os primeiros, vinculados aos direitos da personalidade, são inalienáveis e irrenunciáveis (art. 27); os segundos são transferíveis a terceiros e negociáveis (art. 30). Entretanto, esta função econômica do direito autoral comporta um sistema de restrições ${ }^{7}$ com base em sua função social. Isto significa que há hipóteses em que uma obra, ainda que dentro do prazo de proteção autoral, pode ser utilizada por terceiros independentemente de autorização prévia ou pagamento ao titular ou seus representantes. ${ }^{8}$

Segundo Guilherme Carboni (2006, p. 71), o direito autoral tem quatro funções: (a) identificar o autor; (b) função promocional, como estímulo à produção intelectual; (c) função de política cultural e (d) função econômica. Como os vídeos postados pelo Canal "Não Famoso" são monetizados, a ONErpm amparou-se no princípio da fiscalização do aproveitamento econômico das obras sob sua tutela e solicitou a Daniel que metade da receita auferida por ele com os vídeos lhe fosse repassada. Diante da resposta negativa do autor das paródias, a ONErpm dirigiu-se ao Youtube e alegou que os vídeos postados infringiam direitos autorais, logo iam contra seus Termos de Serviço.

Ocorre que as paródias fazem parte do conjunto de limitações legais aos direitos autorais, ou seja, quando não é necessário pedir autorização do titular e tampouco pagar para utilizar as obras, na forma do art. 47 da LDA: "São livres as paráfrases e paródias que não forem verdadeiras reproduções da obra originária nem lhe implicarem descrédito". Claramente as duas paródias não trazem descrédito para as obras originais, além de utilizarem letras e

\footnotetext{
${ }^{6} \mathrm{O}$ referido procedimento consiste em envio de notificação ao You Tube por parte do titular de obra protegida pela legislação dos direitos autorais - ou de um agente autorizado pelo primeiro - reportando violação a esses direitos. Segundo a política do You Tube, o "reclamante" deve se certificar previamente se o uso da obra protegida por terceiro foi justo ou se é considerado tolerado pela legislação, como, por exemplo, as condutas descritas no art. 46 da LDA.

7 Arts. 46 a 48 da LDA.

${ }^{8}$ É o caso, por exemplo de reprodução em exemplar único, de pequenos trechos de obra literária, para uso privado do copista e de citação em livros, jornais e revistas.
} 
contextos absolutamente distintos, conforme é possível se verificar pelas letras abaixo, transcritas abaixo:

Tabela I - Comparativo das letras da música $10 \%$

\begin{tabular}{|l|l|}
\hline \multicolumn{1}{|c|}{ Trecho de 10\% (original) } & \multicolumn{1}{c|}{ Trecho de 10\% (paródia) } \\
\hline Tô escorada na mesa & Fui experimentar a sobremesa \\
Confesso que eu quase caí da cadeira & Mas confesso que eu já estava com a barriga \\
E esse garçom não me ajuda & cheia \\
Já trouxe a vigésima saideira & E quem mandou ser zoiúda \\
& Agora quero peidar e a situação tá feia \\
Já viu o meu desespero & Já me bateu desespero \\
E aumentou o volume da televisão & É começo de namoro isso não rola não \\
Sabe que sou viciada & Pode até dar em nada \\
E bebo dobrado ouvindo um modão & Mas é mais provável que ele fuja do salão \\
& Não escutei mais nada do que ele falou \\
A terceira música nem acabou & Tô tão concentrada que a minha cara já bugou \\
Eu já tô lembrando da gente fazendo amor & É muita pressão \\
Celular na mão, mas ele não tá tocando & Eu já nem tô respirando \\
Se fosse ligação, nosso amor seria engano, seria \\
engano & Um movimento brusco e a bunda acaba com meu \\
& plano \\
Garçom, troca o DVD & Eu nem sei se vai feder \\
Que essa moda me faz sofrer & Mas eu não vou pagar pra ver vai que ele não \\
E o coração não guenta & aguenta \\
Desse jeito você me desmonta & Quando eu peido até eu fico tonta \\
Cada dose cai na conta e os $10 \%$ aumenta & Ele tá pagando a conta \\
Garçom, troca o DVD & Se morrer me encrenca \\
Que essa moda me faz sofrer & \\
E o coração não guenta & {$[\ldots]$} \\
Desse jeito você me desmonta & \\
Cada dose cai na conta e os $10 \%$ aumenta & \\
[...] & \\
Fo & \\
\hline
\end{tabular}

Fonte: Elaboração própria.

Tabela II - Comparativo das letras da música Malandramente e Medonhamente

\begin{tabular}{|l|l|}
\hline \multicolumn{1}{|c|}{ Trecho de Malandramente (original) } & Trecho de Medonhamente (paródia) \\
\hline Malandramente & Medonhamente \\
A menina inocente & Sem ter nada na frente \\
Só pra poder curtir & Eu sou meio dormente \\
& Tropecei e caí \\
Malandramente & Medonhamente \\
Fez cara de carente & Se o vidro é transparente \\
Envolvida c'a tropa & Dou com os beiço na porta \\
& Todos olham pra mim \\
Começou a seduzir & Medonhamente \\
Malandramente & Me atrapalho do nada \\
Meteu o pé pra casa & Escorrego no banho \\
\hline
\end{tabular}




\begin{tabular}{|l|l|}
\hline Diz que a mãe tá ligando & Olha o poste aí \\
Nós se vê por ai & A escada \\
Ai safada! & É sempre uma missão arriscada \\
Na hora de ganhar madeirada & Pra uma pessoa destrambelhada \\
A menina meteu o pé pra casa & Que não dá dois passos sem distrair \\
E mandou um recadinho pra mim & \\
& Olha o poste aí \\
(Nós se vê por aí) & Olha o poste aí \\
(Nós se vê por aí) & Olha o poste aí \\
(Nós se vê por aí) & Olha o poste aí \\
(Nós se vê por aí) & {$[\ldots]$} \\
[...] & \\
\hline
\end{tabular}

Fonte: Elaboração própria.

Percebe-se que não há nenhum potencial de confusão entre as obras originais e as paródias, tampouco ato de concorrência desleal, conforme alegado pela ONErpm nos processos a serem analisados.

Sendo assim, respeitando-se as funções dos direitos autorais e os dispositivos legais, mesmo que as obras derivadas (paródias) tenham retorno financeiro, esse pertence a quem criou o conteúdo secundário. A legislação brasileira não impede a exploração econômica de paródias. Neste sentido, inclusive, já se posicionou o Superior Tribunal de Justiça (STJ) no Recurso Especial 1548849/SP, citado pelo Desembargador Saul Steil, relator do acórdão do Tribunal de Justiça do Estado de Santa Catarina no caso da paródia da música "10\%":

RECURSO ESPECIAL. ART. 535 DO CPC/1973. FOLHA SE [sic] SÃO PAULO E FALHA DE SÃO PAULO. DIREITO DE MARCA X DIREITO AUTORAL. PARÓDIA. ADAPTAÇÃO DE OBRA JÁ EXISTENTE A UM NOVO CONTEXTO. VERSÃO DIFERENTE, DEBOCHADA. LIMITAÇÃO DO DIREITO DE AUTOR. INEXISTÊNCIA DE CONOTAÇÃO COMERCIAL. PRESCINDÍVEL. CONCORRÊNCIA DESLEAL NÃO CONFIGURADA. [...]

2. O princípio da especialidade é comando limitativo do direito exclusivo da marca, a indicar que referido direito não é absoluto (art. 124, XIX, Lei $n$. 9.279/1996). A exclusividade do uso do sinal distintivo somente é oponível a produtos ou serviços idênticos, semelhantes ou afins, com o fim de evitar que o consumidor seja induzido em erro ou associe determinado produto com outro, de marca alheia. Autoriza-se, assim, a coexistência de marcas idênticas, desde que os respectivos produtos ou serviços pertençam a ramos de atividades diversos.

3. No caso dos autos, no entanto, a disposição do direito marcário não deve ser invocada para solução da controvérsia. É que as duas empresas envolvidas na demanda, apesar de possuírem nomes semelhantes, Falha e Folha de São Paulo, prestam serviços, em tudo, diversos. Uma (Falha) produz crítica aos posicionamentos políticos e ideológicos da outra (Folha), sem a possibilidade de serem concorrentes. A Falha produz paródia com base nas matérias 
produzidas pela Folha, expressando-se, declaradamente, de modo contrário às opiniões expostas pelo jornal, por meio da sátira e do humor.

4. A paródia é forma de expressão do pensamento, é imitação cômica de composição literária, filme, música, obra qualquer, dotada de comicidade, que se utiliza do deboche e da ironia para entreter. É interpretação nova, adaptação de obra já existente a um novo contexto, com versão diferente, debochada, satírica.

5. Assim, a atividade exercida pela Falha, paródia, encontra, em verdade, regramento no direito de autor, mais específico e perfeitamente admitida no ordenamento jurídico pátrio, nos termos do direito de liberdade de expressão, tal como garantido pela Constituição da República.

6. A paródia é uma das limitações do direito de autor, com previsão no art. 47 da Lei 9.610/1998, que prevê serem livres as paráfrases e paródias que não forem verdadeiras reproduções da obra originária nem lhe implicarem descrédito. Essas as condições para que determinada obra seja parodiada, sem a necessidade de autorização do seu titular.

7. A falta de conotação comercial é requisito dispensável à licitude e conformidade da manifestação do pensamento pela paródia, nos termos da legislação de regência (art. 47 da Lei n. 9.610/1998).

8. Não há falar, no caso dos autos, em concorrência desleal. A uma, porque a questão é definida no âmbito da Lei de Marcas (Lei n 9.279/96), não invocada para a solução dessa demanda. A duas, porque, dentre as condutas que tipificam a concorrência desleal não está a conotação comercial, da qual a Falha fora acusada.

9. Recurso especial parcialmente provido." (REsp 1548849/SP, Rel. Min. Marco Buzzi, Rel. p/ Acórdão Min. Luis Felipe Salomão, Quarta Turma, julgado em 20/06/2017, DJe 04/09/2017. [grifos nossos]

Registra-se que o You Tube prevê um instrumento de contra-notificação ao procedimento de "notice and take down" previsto nos seus Termos de Serviço. Entretanto, ao invés de viabilizar em tese a defesa do autor do conteúdo reclamado, o procedimento é assaz falho, como se demonstra a partir da transcrição parcial de seu conteúdo.

B. Contra-Notificação. Se você acredita que seu conteúdo foi removido (ou cujo acesso foi desativado) não consiste em infração, ou que você tenha autorização do detentor dos direitos autorais, do representante do detentor ou nos termos da lei para enviar e usar o conteúdo, você pode enviar uma contra-notificação ao Representante de Direitos Autorais contendo as seguintes informações:

- Assinatura física ou eletrônica;

- Identificação do conteúdo removido ou cujo acesso foi desativado e local onde o conteúdo apareceu antes de ser removido ou desativado;

- Declaração de que você acredita de boa-fé que o conteúdo foi removido ou desativado em consequência de equívoco ou má interpretação do conteúdo; e - Nome, endereço, número de telefone e endereço eletrônico, declaração de que se submete à jurisdição do tribunal federal de São Francisco, na Califórnia, e declaração de que receberá entrega de citação da pessoa que apresentou a notificação sobre a suposta infração. 
Se o Representante de Direitos Autorais receber uma contra-notificação, o Youtube poderá enviar uma cópia da contra-notificação ao reclamante original informando que o conteúdo removido poderá ser recolocado no site ou seu acesso reativado em 10 dias úteis. Se o detentor dos direitos autorais não ajuizar uma ação solicitando ordem judicial contra o provedor de serviços, membro ou usuário, o conteúdo removido poderá ser recolocado, ou seu acesso restaurado, de 10 a 14 dias úteis ou mais após o recebimento da contra-notificação, a critério exclusivo do Youtube. [grifos nossos]

Percebe-se, de acordo com os Termos de Serviço do Youtube, que o conteúdo é primeiro removido (após a primeira notificação) para então ser contra-notificado o reclamado. O procedimento se assemelha a uma concessão em caráter initio litis (antecipatório), sem as garantias judiciais. Além disso, o Youtube deveria incluir em seus Termos de Serviço as exceções legais às violações de direitos autorais, como é o caso da paródia, comportamento expressamente autorizado pela legislação brasileira.

Com base nesse mecanismo de notificação e contra-notificação, os dois vídeos do criador do Canal "Não Famoso", apesar de perfeitamente legais, foram retirados da página e outros seis tiveram as receitas revertidas diretamente para as gravadoras das músicas originais. Em relação às paródias das músicas "10\%" e "Malandramente", ambas voltaram a ser exibidas no Canal "Não Famoso" catorze dias após a contra-notificação. Durante este período, Daniel Cândido dos Santos deixou de auferir lucros e nada foi feito pelo You Tube a respeito da notificação indevida da ONErpm e do procedimento equivocado da plataforma.

Diante deste prejuízo e da privação de rendimentos durante o tempo de retirada dos vídeos, Daniel ajuizou ação de obrigação de fazer cumulada com pedido indenizatório por danos morais e materiais ${ }^{9}$ em face de ONErpm Comércio e Serviços de Mídia Digital Ltda. e Google Brasil Internet Ltda. (proprietário do Youtube). A primeira ré sustentou a violação do direito autoral e que,, como representante dos interesses do autor e intérpretes da música parodiada, deve defender seus direitos em caso de violação, pugnando pela improcedência dos pedidos.

Google Brasil Internet Ltda. arguiu a perda de objeto do pedido pela reativação do vídeo, suscitando, ainda, preliminar de ilegitimidade passiva, sob a alegação de que atua de acordo com os Termos de Serviço do Youtube, sendo apenas um provedor de aplicações de internet, de modo que "não se pode esperar do provedor de hospedagem atividades de

\footnotetext{
${ }^{9}$ A pretensão autoral tem por fundamento o art. 402 do Código Civil, segundo o qual, salvo as exceções expressamente previstas em lei, as perdas e danos devidas ao credor (vítima do ato ilícito) abrangem, além do que ele efetivamente perdeu, o que razoavelmente deixou de lucrar.
} 
fiscalização". O segundo réu argumentou que seus Termos de Serviço são claros em relação à política referente aos direitos autorais e que o art. 19 da Lei n. 12.965/2014 (Lei do Marco Civil da Internet), a seguir transcrito, só lhe impõe responsabilidade por conteúdo postado ou gerado por terceiros em caso de descumprimento de ordem judicial específica:

Art. 19. Com o intuito de assegurar a liberdade de expressão e impedir a censura, o provedor de aplicações de internet somente poderá ser responsabilizado civilmente por danos decorrentes de conteúdo gerado por terceiros se, após ordem judicial específica, não tomar as providências para, no âmbito e nos limites técnicos do seu serviço e dentro do prazo assinalado, tornar indisponível o conteúdo apontado como infringente, ressalvadas as disposições legais em contrário. [...] [grifos nossos]

No caso narrado, não houve ordem judicial específica para a retirada do conteúdo, pois a reclamante se reportou ao Google através do procedimento interno de notificação e esse, após receber a resposta do reclamado (contra-notificação), reinseriu o material atacado no You Tube.

A despeito da argumentação do réu, os desembargadores das Terceira e Sexta Câmaras de Direito Civil do Tribunal de Justiça de Santa Catarina (TJSC) ${ }^{10}$ entenderam que o Google vem distorcendo o teor do caput do art. 19 da Lei do Marco Civil da Internet. Segundo a posição dos julgadores, esse dispositivo legal, em prol da liberdade de expressão e vedação de censura ${ }^{11}$ deve ser interpretado no sentido de que o conteúdo atacado deve ser mantido na Internet até que haja uma ordem judicial determinando sua retirada, e não o contrário.

A interpretação conferida pelo Google ao art. 19 da Lei do Marco Civil da Internet não tem coerência com o ordenamento jurídico pátrio vigente. Como deslinde da ação, em primeiro grau, nos dois processos ONErpm Comércio e Serviços de Mídia Digital Ltda. e Google Brasil Internet Ltda. foram condenadas ao pagamento de $\mathrm{R} \$ 30.000,00$ (trinta mil reais) a título de indenização por danos morais pela remoção indevida dos vídeos. Em segundo grau, as condenações foram mantidas, contudo indenizações foram reduzidas para $\mathrm{R} \$ 10.000,00$ (dez mil reais) por réu e por cada vídeo.

\footnotetext{
${ }^{10}$ Julgamento das Apelações n. 0000447-46.2016.8.24.0175 e 0000412-86.2016.8.24.0175, respectivamente.

${ }^{11}$ A vedação de censura está consagrada no art. 220, caput, e § $2^{\circ}$, ambos da Constituição de 1988: “Art. 220. A manifestação do pensamento, a criação, a expressão e a informação, sob qualquer forma, processo ou veículo não sofrerão qualquer restrição, observado o disposto nesta Constituição. [...] $\S 2^{\circ}$ É vedada toda e qualquer censura de natureza política, ideológica e artística." [grifos nossos]. A vedação à censura também se insere, a contrario sensu, como direito fundamental de primeira dimensão (ou geração), consistente na liberdade individual de expressão da atividade intelectual, artística, científica e de comunicação, independentemente de censura ou licença (art. $5^{\circ}$, IX, da Constituição de 1988). No mesmo sentido, a Lei $\mathrm{n}^{\circ}$ 12.965/2014 em seu art. 19, § 2 ${ }^{\circ}$, resguarda, para infrações relativas a direitos de autor, a liberdade de expressão e demais garantias previstas no art. 5으 da Constituição Federal.
} 
Poucos meses após a condenação em segunda instância do Google, as decisões judiciais citadas provocaram mudanças na política de governança do Youtube no mundo todo, mas as mudanças mais drásticas foram no Brasil, conforme se analisará no tópico seguinte.

\section{A MUDANÇA NA POLÍTICA DE GOVERNANÇA DE DIREITOS AUTORAIS DO YOUTUBE A PARTIR DA ATUALIZAÇÃO DE SEUS TERMOS DE SERVIÇO}

Coincidentemente ou não, todos os Termos de Serviço do Youtube foram atualizados em 25 de maio de 2018, após o julgamento do caso Canal "Não Famoso". Apesar da insistência dos autores através de contatos por email, representantes da Google Brasil Internet Ltda. não informaram os motivos das atualizações, tampouco das mudanças drásticas e unicamente em relação ao Brasil.

Em geral, o cadastro do usuário é opcional para utilizar/acessar a plataforma Youtube; entretanto, torna-se obrigatório nas seguintes situações: (i) publicação de vídeos; (ii) visualização de vídeos com conteúdo adulto; (iii) criação de listas de músicas ou de vídeos (playlists); (iv) avaliação de vídeos e (v) postagem de comentários. Ao se cadastrar, o usuário precisar, necessariamente, concordar e aderir aos Termos de Serviço da plataforma.

A primeira questão diz respeito à política de direitos autorais desta rede social. Apesar de seus Termos de Serviços estarem redigidos em língua portuguesa, o documento faz referência à uma lei estadunidense, a "Digital Millennium Copyright Act" (DMCA). Esta lei, promulgada em 1998, tinha por objetivo atualizar a antiga lei de direito autoral (Copyright Act of 1976) frente aos desafios do mundo digital, mas suas normas foram cercadas de controvérsias, principalmente no que se refere às regras de isenção de responsabilidade por parte dos provedores de internet ${ }^{12}$.

Ao consultar os Termos de Serviço do Youtube em outros países, como por exemplo, Canadá, França, Reino Unido, Austrália e México, percebe-se que o texto informativo é exatamente do mesmo teor do original, dos Estados Unidos, país da sede do Youtube, na localidade de San Bruno, Califórnia, conforme extrato a seguir:

\footnotetext{
12 O Título II da DMCA acrescentou uma nova Seção ao Copyright Act (Seção 512) para criar quatro novas limitações à responsabilidade pela violação de direitos autorais por parte de provedores de serviços on-line. As limitações são baseadas nas quatro categorias de conduta a seguir por um serviço

fornecedor: 1. Comunicações Transitórias (Transitory Digital Network Communications); 2. Cache do sistema (System Caching); 3. Armazenamento de informações sobre sistemas ou redes na direção dos usuários (Information Residing on Systems or Networks at Direction of Users); e 4. Ferramentas de localização de informações (Information Location Tools). A nova Seção 512 também inclui regras especiais relativas à aplicação dessas limitações às instituições educacionais sem fins lucrativos.
} 
Política de Direitos Autorais

O Youtube aplica uma clara política de direitos autorais em relação a qualquer conteúdo que alegadamente infrinja direitos de terceiros. Detalhes desta política podem ser encontrados aqui: https://www.youtube.com.au/t/copyright notice.

Como parte da política de direitos autorais do Youtube, a plataforma vai encerrar o acesso do usuário ao serviço se houver infrações reiteradas. Um usuário reincidente é aquele que foi notificado sobre atividades irregulares mais de duas vezes. ${ }^{13}$

Especificamente no caso brasileiro, o item dos Termos de Serviço que trata da política de direitos autorais da plataforma destoa (e muito) do que se verificou nos demais países acima listados. Além de o texto ser enorme e cheio de detalhes, menciona explicitamente a aplicação da legislação norte- americana para tratar de questões referentes a direito autoral, in verbis:

Lei Millenium (Millenium Act) de Autoria Digital

Se você for detentor de direito autoral ou representante de um detentor de direito autoral e acredita que qualquer conteúdo infringe seus direitos autorais, você poderá enviar uma notificação conforme a Lei Millenium de Autoria Digital (Digital Millennium Copyright Act - "DMCA"), fornecendo ao nosso Representante de Direitos Autorais as seguintes informações por escrito (veja 17 U.S.C 512(c)(3) para mais detalhes):

- Assinatura física ou eletrônica da pessoa autorizada a agir em nome do proprietário do direito exclusivo supostamente infringido;

- Identificação do trabalho protegido por direito autoral supostamente infringido, ou se vários trabalhos protegidos por direito autoral em um único site on-line forem incluídos em uma única notificação, enviar uma lista representativa de tais trabalhos naquele site;

- Identificação do material supostamente infringido ou objeto de atividade infratora que deve ser removido, ou cujo acesso deve ser desativado, com informações razoavelmente suficientes para permitir ao provedor de serviço localizar o material;

- Informações razoavelmente suficientes para permitir ao provedor de serviços contatá-lo, tais como endereço, número de telefone e, se possível, endereço eletrônico;

- Declaração de que você acredita de boa-fé que o uso do material da forma reclamada não foi autorizado pelo detentor do direito autoral, por seu representante ou pela lei; e

- Declaração de que a informação constante da notificação é precisa e, sob pena de sofrer as penalidades previstas na lei, de que você está autorizado a

13 Tradução livre. Texto original, em inglês:

8. Copyright Policy

YouTube operates a clear copyright policy in relation to any Content alleged to infringe the copyright of a third party. Details of that policy can be found here https://www.youtube.com.au/t/copyright notice.

As part of YouTube's copyright policy, YouTube will terminate user access to the Website if a user has been determined to be a repeat infringer. A repeat infringer is a user who has been notified of infringing activity more than twice. 
agir em nome do proprietário do direito exclusivo que está supostamente sendo infringido ${ }^{14}$. [grifos nossos]

É notório que tanto as sociedades nacionais quanto as estrangeiras, essas após a concessão de autorização para funcionar, ficam sujeita às leis e aos tribunais brasileiros quanto aos atos ou operações praticados no Brasil (art. 1.137, caput, do Código Civil). Por conseguinte, a Google Brasil Internet Ltda. não pode impor - num termo de adesão - a aplicação da lei estadunidense em detrimento da legislação nacional, ou ainda, exigindo informações previstas na DMCA. Além de não ser hipótese de aplicação extraterritorial da lei, a prática viola o art. $5^{\circ}$, II, da Constituição de 1988 ("ninguém será obrigado a fazer ou deixar de fazer alguma coisa senão em virtude de lei”), bem como procura afastar o diploma específico sobre o assunto, a Lei n. 9.610/98 - LDA.

Da leitura dos Termos de Serviço para os usuários brasileiros, consta no início das Disposições Gerais:

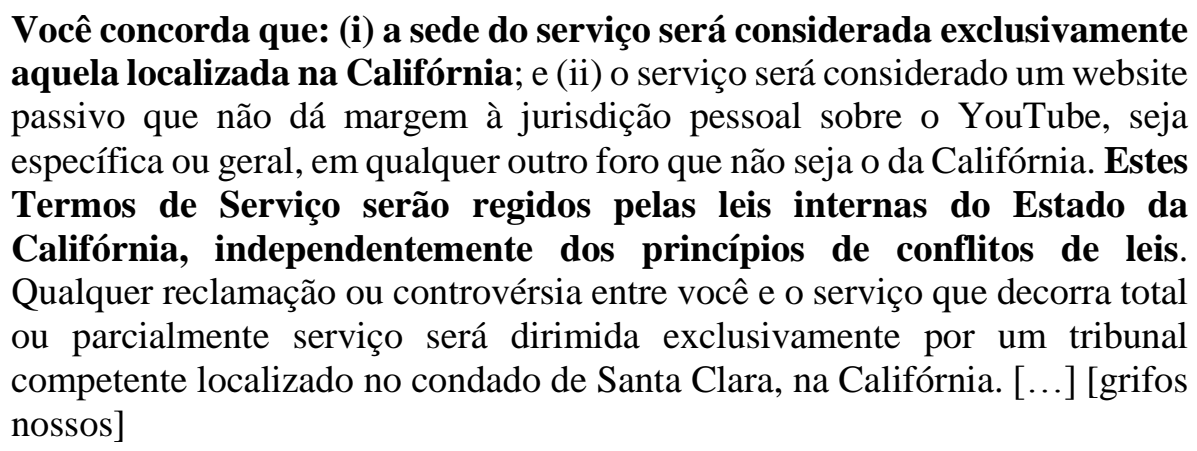

Percebe-se que a menção à lei estadunidense se dá em virtude da fixação do foro na Califórnia, com afastamento de qualquer outro, por imposição unilateral do provedor. Além disso, o Google fixou (em letras maiúsculas) o prazo prescricional de 1 (um) ano para ajuizamento da demanda, conforme segue:

\footnotetext{
${ }^{14}$ As informações escritas são exatamente aquelas exigidas na Seção 512, item C (Information Residing on Systems or Networks At Direction of Users), n. 3 (Elements of notification), consoante extrato do texto da lei em inglês: (i) a physical or electronic signature of a person authorized to act on behalf of the owner of an exclusive right that is allegedly infringed; (ii) identification of the copyrighted work claimed to have been infringed, or, if multiple copyrighted works at a single online site are covered by a single notification, a representative list of such works at that site; (iii) identification of the material that is claimed to be infringing or to be the subject of infringing activity and that is to be removed or access to which is to be disabled, and information reasonably sufficient to permit the service provider to locate the material; (iv) information reasonably sufficient to permit the service provider to contact the complaining party, such as an address, telephone number, and, if available, an electronic mail address at which the complaining party may be contacted; (v) a statement that the complaining party has a good faith belief that use of the material in the manner complained of is not authorized by the copyright owner, its agent, or the law; (vi) a statement that the information in the notification is accurate, and under penalty of perjury, that the complaining party is authorized to act on behalf of the owner of an exclusive right that is allegedly infringed.
} 
Você e o YouTube concordam que qualquer ação judicial oriunda ou relacionada ao serviço deve ser iniciada no período de 1 (um) ano após a ocorrência da causa de pedir. Do contrário, o direito prescreverá. [grifos nossos]

Claramente, a ilação que se pode adotar é que o texto acima ignora as disposições mais favoráveis que as leis locais podem conferir aos usuários da plataforma no tocante à aplicação da lex fori (v.g. foro do país de nacionalidade ou domicílio do usuário), e não da sede contratual, tomada em caráter absoluto como "sede do serviço", bem como a previsão de prazos prescrionais superiores a 1 (um) ano, como a propósito dispõem os arts. 27 e 101, I, do Código Brasileiro de Defesa do Consumidor (Lei n. 8.078/1990).

Ao verificar os Termos de Serviço do Youtube do Brasil e de outros 11 países, eis a sistematização do resultado encontrado:

Tabela III - Termos de Serviço do Youtube (após 25/05/2018) ${ }^{15}$

\begin{tabular}{|c|c|c|c|}
\hline Região ou Continente & País & $\begin{array}{l}\text { Lei aplicável para } \\
\text { solução de } \\
\text { controvérsias }\end{array}$ & $\begin{array}{l}\text { Prazo prescricional } \\
\text { para propositura da } \\
\text { ação }\end{array}$ \\
\hline \multirow[t]{3}{*}{ América Latina } & Brasil & Califórnia, E.U.A. & 1 ano \\
\hline & Argentina & Califórnia, E.U.A. & 1 ano \\
\hline & Uruguai & Califórnia, E.U.A. & 1 ano \\
\hline \multirow[t]{2}{*}{ América Central } & México & Califórnia, E.U.A. & 1 ano \\
\hline & Panamá & Califórnia, E.U.A. & 1 ano \\
\hline América do Norte & Canadá & Califórnia, E.U.A. & 1 ano \\
\hline \multirow[t]{4}{*}{ Europa } & Reino Unido & Britânica & Não menciona \\
\hline & França & Francesa & Não menciona \\
\hline & Espanha & Espanhola & Não menciona \\
\hline & Bélgica & Belga & Não menciona \\
\hline Oceania & Austrália & Califórnia, E.U.A. & 1 ano \\
\hline África & África do Sul & Califórnia, E.U.A. & 1 ano \\
\hline
\end{tabular}

Fonte: Elaboração própria.

Pelos dados coletados acima, percebe-se que, no final de maio de 2018, o Youtube modificou sua política de governança através da atualização dos Termos de Serviço. A grande mudança está na imposição do foro do Estado da Califórnia, Estados Unidos, e,

15 Os links para a íntegra dos Termos de Serviço para os usuários dos países pesquisados encontram-se listados nas Referências. 
consequentemente, da Lei Millenium para todos os países que não façam parte da União Europeia. Isso porque as hipóteses de responsabilização do provedor na Digital Millennium Copyright Act são bem mais restritas. ${ }^{16}$ Além disso, chama a atenção a fixação de prazo prescricional de 1 (um) ano para ajuizamento de demandas que envolvam a rede social, prazo esse também restrito a países de fora da União Europeia.

Por fim, a atualização dos Termos de Serviço do YouTube enfatizou que as atualizações nas políticas de governança não precisam ser previamente avisadas aos usuários, e que cabe a eles reler de tempos em tempos o documento, a fim de verificar se houve alguma modificação, como se nota no extrato infra.

O YouTube se reserva o direito de alterar estes Termos de Serviço a qualquer tempo e sem aviso, e é sua responsabilidade em reler estes Termos de Serviço para verificar a ocorrência de qualquer alteração. $\mathrm{O}$ uso do serviço por você após qualquer aditamento aos Termos de Serviço implicará o consentimento e a aceitação dos termos aditados. [grifos nossos]

Ora, é no mínimo risível e desproporcional exigir o provedor que esta atualização fique por conta dos usuários, sem aviso prévio, e com o ônus de reler a todo acesso os Termos de Serviço, para verificar se houve alguma alteração com a qual eventualmente não concordará.

É muito mais coerente que a plataforma, detentora do cadastro de todos os usuários, lhes envie uma mensagem/aviso informando a alteração dos termos de uso e exija-lhes a anuência para continuarem usufruindo dos serviços. A atual política de governança da plataforma conduz para um inequívoco vício de consentimento, por desconhecimento das regras que mudam unilateralmente e sem aviso prévio.

\section{A TENTATIVA DO GOOGLE DE SUBTRAIR-SE À JURISDIÇÃO LOCAL E SEU EFEITO PARA A GOVERNANÇA MULTISSETORIAL DA INTERNET}

\footnotetext{
${ }^{16}$ Como se extrai do teor do 17 U.S.Code $\$ 512$ (b): (1) - Limitations on liability relating to material online. A service provider shall not be liable for monetary relief, or, except as provided in subsection (j), for injunctive or other equitable relief, for infringement of copyright by reason of the intermediate and temporary storage of material on a system or network controlled or operated by or for the service provider in a case in which

(A) the material is made available online by a person other than the service provider;

(B) the material is transmitted from the person described in subparagraph (A) through the system or network to a person other than the person described in subparagraph (A) at the direction of that other person; and

(C) the storage is carried out through an automatic technical process for the purpose of making the material available to users of the system or network who, after the material is transmitted as described in subparagraph (B), request access to the material from the person described in subparagraph (A), if the conditions set forth in paragraph (2) are met.
} 
Através da análise da última alteração nos Termos de Serviço do Youtube, fica a impressão de que a política de governança do Google é atuar no mundo todo, mas só se submeter às leis estadunidenses ou às leis da União Europeia. O que poderia parecer uma ocorrência isolada pode ser corroborado com outro recente comportamento do provedor, em 2017, para evadir-se da jurisdição local, neste caso a canadense.

Uma sociedade de tecnologia da informação (TI) - Equustek Solutions Inc. - produzia complexos dispositivos de rede, distribuídos pela Datalink. Segundo a Equustek, a Datalink teria re-etiquetado um de seus produtos para vender como se fosse produção própria e, além disso, teria se valido de seus segredos de negócios e informações confidenciais para produzir produtos falsificados, aumentando sua receita às custas da distribuída.

Dscoberta a fraude, a Equustek rescindiu o contrato e exigiu que a Datalink eliminasse qualquer referência à sua marca ou aos seus produtos do seu sítio na Internet. Em 2011, a Equustek processou o diretor da Datalink e duas subsidiárias por apropriação indevida de propriedade intelectual. Após o início da demanda, a Datalink se evadiu da jurisdição canadense e manteve suas operações online armazenando os produtos em local físico desconhecido.

Houve diversas decisões interlocutórias ao longo do processo e, ao final mas ainda em 2011, o tribunal canadense ordenou que a Datalink devolvesse toda a documentação relativa aos produtos da Equustek e se abstivesse de mencionar seus produtos online. Em 2012, a Corte determinou a apreensão de todos os bens da Datalink no mundo inteiro. Entretanto, decisões no mundo offline nem sempre surtem os efeitos desejados no mundo online.

Como ainda assim a Datalink mantivesse suas operações na internet, a Equustek solicitou ao Google que a desindexasse, ou seja, parasse de listar em sua ferramenta de busca os sites da Datalink. O Google, por sua vez, exigiu uma ordem judicial.

Na sequência, o tribunal canadense determinou que a Datalink não operasse ou mantivesse quaisquer negócios em nenhum endereço eletrônico. Com base na ordem judicial, o Google removeu 345 páginas relacionadas com a Datalink do domínio "google.ca" (Google Canadá), mas se recusou a retirar os demais endereços eletrônicos ainda existentes no seu domínio global (google.com).

A Datalink transferiu todo o seu conteúdo para outros domínios não foram atingidos pela ordem judicial e o conteúdo contestado pela Equustek continuava visível nos resultados de busca. Diante da situação, a Equustek processou o Google e conseguiu uma liminar para que o buscador removesse todos os sítios da Datalink da ferramenta de busca no mundo inteiro. 
O Google interpôs recurso para a Corte de Apelação da Província de Columbia Britânica, que confirmou a liminar. Não satisfeito, o Google recorreu para a Suprema Corte do Canadá. Os argumentos do buscador podem ser resumidos em três pilares: (i) a medida ofenderia a cooperação internacional; (ii) oneraria de forma irrazoável a ferramenta de busca e (iii) interferiria no direito à liberdade de expressão.

Os argumentos levantados pelo Google não foram suficientes para convencer a Suprema Corte canadense, que entendeu ser necessária a medida de desindexação mundial de todos os domínios da ré (Datalink) para evitar danos irreparáveis à autora (Equustek) diante da violação à propriedade intelectual.

Após perder os recursos em todas as instâncias canadenses, o Google conseguiu uma liminar na Corte Distrital do Estado da Carolina do Norte (Estados Unidos) para bloquear os efeitos da decisão da Suprema Corte do Canadá.

O caso Equustek é de suma importância, pois desafia diversas questões que precisam ser meticulosamente analisadas, tais como: (i) extraterritorialidade de determinadas leis/ decisões e (ii) tratados internacionais sobre comércio e concorrência desleal.

Embora as questões ventiladas fujam aos estreitos limites de extensão e escopo deste artigo, a narrativa dos acontecimentos é importante para permitir a reflexão de que, nesse e no caso dos Termos de Uso do Youtube, percebe-se, aparentemente, a intenção do Google de buscar a jurisdição de outro país para obter decisões que lhe favoreçam.

A política de fuga à jurisdição local por parte do Google é um desafio em termos de governança da Internet, num mundo cada vez mais dominado por sociedades empresárias que têm lucros maiores do que produtos internos brutos (PIBs) de muitos países.

Diante das práticas perpetradas pelo Google, de certa forma há uma negação ao modelo de governança da Internet quando esse impõe aos provedores de conteúdo uma responsabilização maior do que a legislação dos Estados Unidos, mesmo para proteger a propriedade intelectual. Entretanto, a concepção de governança compreende um conjunto mais amplo de atividades de controle, que transcendem as diretrizes e ações adotadas pelo Estado.

No Brasil existem diretrizes fixadas para a atuação da União, dos Estados, do Distrito Federal e dos Municípios no desenvolvimento da internet no Brasil, dispostas no art. 24 da Lei n. 12.965/2014, dos quais se destaca o estabelecimento de mecanismos de governança multiparticipativa, transparente, colaborativa e democrática, com a participação do governo, do setor empresarial, da sociedade civil e da comunidade acadêmica (inciso I). 
Percebe-se que a Lei do Marco Civil adotou um modelo de governança multissetorial da internet (multistakeholder governance) onde convivem atores públicos (governo) e privados (empresários, sociedade civil e comunidade acadêmica). Esse modelo de governança tem sua origem na iniciativa da Organização das Nações Unidas, em 2003, de realizer a Cúpula Mundial da Sociedade da Informação - CMSI. Desde a primeira reunião em Genebra, Suíça, um grupo de trabalho sobre governança da internet ficou responsável por apresentar o conceito de governança da Internet:

A governança da Internet é o desenvolvimento e a aplicação pelos governos, setor privado e sociedade civil, em seus respectivos papéis, de princípios, normas, regras, procedimentos de tomada de decisão e programas compartilhados que moldam a evolução e o uso da Internet.

O conceito de governança apresentado foi aprovado em 2005 na segunda reunião da CMSI, em Túnis, Tunísia. Segundo Thiago Moraes (2016, p. 81), houve a nível mundial um reconhecimento de que a Internet é um espaço pluriparticipativo, protagonizado não só pelos Governos, mas também por atores do setor privado e da sociedade civil.

Com base na premissa acima, afirma-se que não há prevalência na governança da Internet dos interesses de um grupo ou ator sobre outro(s). Não cabe a negação da jurisdição de um país em detrimento do outro, ou ainda que a lei de um Estado norte-americano possa ter o status de uma convenção ou tratado internacional implicitamente ratificado e internalizado em todos os países nos quais o provedor de conteúdo atua por meio de suas subsidiárias ou agentes autorizados.O modelo de governança multissetorial deriva do item 49 da Declaração de Princípios da $\mathrm{CMSI}^{17}$, aprovada em 2005. Este modelo foi adotado pelo Fórum de Governança da Internet criado em 2006 pela Assembleia Geral da ONU. No ordenamento brasileiro, o modelo foi traduzido como "multissetorial", em virtude da adoção

\footnotetext{
${ }^{17}$ Eis a redação do item 49. A gestão da Internet abrange tanto as questões técnicas quanto as de políticas públicas e deve envolver todas as partes interessadas e as organizações intergovernamentais e internacionais relevantes. A esse respeito, reconhece-se que: a) a autoridade política para questões de políticas públicas relativas à Internet é direito soberano dos Estados. Eles têm direitos e responsabilidades para com as questões internacionais de políticas públicas relativas à Internet; b) o setor privado tem tido e deve continuar tendo um importante papel no desenvolvimento da Internet, tanto no campo técnico como no econômico; c) a sociedade civil também tem desempenhado um importante papel nas questões relativas à Internet, especialmente em nível comunitário, e deve continuar a desempenhar tal papel; d) as organizações intergovernamentais têm tido e devem continuar tendo um papel facilitador na coordenação das questões de políticas públicas relativas à Internet; e) as organizações internacionais também têm tido e devem continuar tendo um importante papel no desenvolvimento dos padrões técnicos e das políticas relevantes relacionados à Internet.

A íntegra do documento pode ser encontrada em http://www.fbln.pro.br/downloadable/pdf/CMSI_declaracaoprincipios_Genebra2003.pdf
} 
do termo pelo Comitê Gestor da Internet no Brasil (CGI.br), instituído em 1995 com a atribuição de gerenciar a estrutura lógica da Internet brasileira.

Para Kimberly Anastacio (2015, p. 22), o modelo multissetorial é "a união de duas ou mais classes de atores engajadas em assuntos considerados públicos por natureza dentro de um ambiente comum de governança caracterizado por relações poliárquicas de autoridade firmadas através de normas processuais". Portanto, é um modelo que almeja harmonizar os interesses do governamentais, dos mercados econômicos tradicionais e dos cidadãos.

No caso brasileiro, o modelo multissetorial não só é defendido como adotado pelo Comitê Gestor da Internet no Brasil, que apresenta estrutura pluriparticipativa em sua composição, onde membros do governo, do setor empresarial, da sociedade civil e comunidade acadêmica participam dos processos decisórios (DIREITO, 2010). Flávio Rech Wagner e Diego Rafael Canabarro (2014) destacam que a governança da internet no Brasil é reconhecida como modelo de excelência devido ao modelo pluriparticipativo adotado.

A vista das considerações, percebe-se como são importantes as decisões do Tribunal de Justiça de Santa Catarina quando proclamou a licitude das paródias das músicas veiculadas no Canal "Não Famoso" embasado na aplicação da legislação brasileira sobre direitos autorais e as disposições constitucionais, na linha da governança multissetorial quando os interesses públicos se coadunam com os interesses privados.

\section{CONSIDERAÇÕES FINAIS}

Diversos fatores podem motivar mudanças na política de governança de sociedades empresárias com atuação em escala mundial: instabilidade política, econômica e insegurança jurídica. A concepção de insegurança jurídica geralmente está associada ao fator surpresa de mudança repentina do posicionamento dos tribunais ou dos legisladores, sinalizando fragilidade e instabilidade na elaboração, aplicação ou interpretação das leis.

Sem embargo, nos dois casos analisados neste artigo, não houve por parte do Tribunal de Justiça do Estado de Santa Catarina nenhum ativismo judicial nas decisões condenatórias das sociedades ONErpm Comércio e Serviços de Mídia Digital Ltda. e Google Brasil Internet Ltda.. Ao contrário, ambas são tecnicamente corretas e inatacáveis, pois se baseiam em princípios constitucionais, invocam acertadamente direitos fundamentais de primeira geração, interpretam de modo harmonioso as Leis n 9.610/1998 e 12.965/2014 e são consentâneas com os atos "toleráveis" pelos titulares de direitos autorais, que não atentam contra eles, na forma da LDA, notadamente em seu art. 47. 
Não há como negar que o Youtube, desde o início de suas atividades em 2005, tenha grandes e justificadas preocupações com a ocorrência de violações de direitos autorais em sua plataforma. Entretanto, o fato de atuar em países com legislações diversas sobre o tema deveria ser razão de adaptação de seus Termos de Serviço às leis locais (lex loci), e não a imposição de foro do país de sua sede (lex fori), fato que, na prática, poderá ser afastado pelas autoridades judiciárias locais quando houver litígio. A postura impositiva e veladamente opressora do Google mostra-se perigosa, na medida em que sinaliza esforços para evadir-se da jurisdição local, como no caso da Equustek, embora em certos países os Termos de Serviço aceitem a aplicação da lex loci como lex fori.

Além disso, a alteração de seus Termos de Serviço sem notificação e nova anuência dos usuários demonstra uma forma de governança não transparente, que atinge o usuário "de surpresa" e deve ser rechaçada veementemente. Uma sociedade empresária do porte da Google Incorporation tem plenas condições de implementar Termos de Serviço em consonância com as leis locais, como o faz em certos países, ao invés de simplesmente traduzir os Termos utilizados nos Estados Unidos pela comodidade e conveniência de ser o país de sua sede.

Sem um posicionamento oficial do Google não é possível afirmar categoricamente que tais alterações nos Termos de Serviço ao redor do mundo foram motivadas pelos resultados dos julgamentos brasileiros, contudo, pela cronologia dos fatos, há um indício forte de que estas decisões interferiram na governança da plataforma.

\section{REFERÊNCIAS}

ALEXA. Top sites. Disponível em: 〈https://www.alexa.com/topsites $>$. Acesso em 03 de set. 2018.

ANASTACIO, Kimberly. Participação na governança da Internet o multissetorialismo do Comitê Gestor da Internet no Brasil (CGI.br). Brasília: Universidade de Brasília, 2015.

BRANCO JUNIOR, Sérgio Vieira. Direitos autorais na internet e o uso de obras alheias. Rio de Janeiro: Lumen Juris, 2007.

BRASIL. Lei n. 9.610 de 19 de Fevereiro de 1998. Altera, atualiza e consolida a legislação sobre direitos autorais e dá outras providências.

. Constituição da República Federativa do Brasil de 1988.

. Lei n. 12.965, de 23 de abril de 2014. Estabelece princípios, garantias, direitos e deveres para o uso da Internet no Brasil. 
. Superior Tribunal de Justiça. Quarta Turma. Recurso Especial 1548849/SP, relator Min. Marco Buzzi, relator para Acórdão Min. Luis Felipe Salomão, julgado em 20 de junho de 2017, DJe 04/09/2017.

CANADÁ. Suprema Corte. Caso. 36602. Google Inc. v. Equustek Solutions Inc. Juízes: McLachlin, Beverley; Abella, Rosalie Silberman; Moldaver, Michael J.; Karakatsanis, Andromache; Wagner, Richard; Gascon, Clément; Côté, Suzanne; Brown, Russell; Rowe, Malcolm. Julgamento em 28 de junho de 2017. Disponível em https://scc-csc.lexum.com/scccsc/scc-csc/en/item/16701/index.do. Acesso em 03 de set. 2018.

CARBONI, Guilherme. Função Social do Direito de Autor. Curitiba: Juruá, 2006.

CARVAlHO, Ana Cristina Azevedo P.. Marco Civil da Internet no Brasil: análise da Lei ${ }^{\circ}$ 12.965/14 e do Direito de Informação. São Paulo: Alta Books, 2014.

DE CEZARO, Bárbara; PIAIA, Thami Covatti. Ativismo Digital no Brasil: Considerações sobre o Marco Civil da Internet. In BARROS, Carla Eugenia Barros; ASSAFIM, João Marcelo de Lima; LIMA, Renata Albuquerque (Coord.). Direito, inovação, propriedade intelectual e concorrência. Florianópolis: CONPEDI, 2015. Disponível on line em https://www.conpedi.org.br/publicacoes/c178h0tg/if08mdi9/JLhfqc23S1GjYhZ0.pdf

DIREITO, Denise do Carmo. Governança da Internet: construção da agenda brasileira negociada em uma realidade de múltiplos atores. 2010. 154 f.: il. Dissertação (Mestrado em Ciência Política) -Universidade de Brasília, Brasília, 2010.

JESUS, Damásio de; MILAGRE, José Antonio. Marco Civil da Internet - Comentários à Lei n. 12.965/14. São Paulo: Saraiva, 2014.

KURBALIJA, Jovan; GELBSTEIN, Eduardo. Governança da Internet: Questões, Atores e Cisões. Tradução de Renato Aguiar. Rio de Janeiro: Núcleo de Pesquisa, Estudos e Formação da Rede de Informações para o Terceiro Setor (Nupef/Rits), 2005.

LEITE, George Salomão; LEMOS, Ronaldo (Coord.). Marco Civil da Internet. São Paulo: Atlas, 2014.

LEMOS, Ronaldo. Direito, Tecnologia e Cultura. Rio de Janeiro: Editora FGV, 2005.

LIMA, Cíntia Rosa Pereira de; DE LUCCA, Newton; SIMÃO FILHO, Adalberto. Direito \& Internet III. Marco Civil da Internet. Lei $n^{\circ}$ 12.965/ 2014 - Tomo 1. São Paulo: Quartier Latin, 2014.

MORAES, Thiago Guimarães. A Governança da Internet e o Sistema de Direitos Autorais no Ambiente Digital. In FREITAS, Cinthia O. A.; BARRETO JUNIOR, Irineu Francisco; BOFF, Salete Oro (Coord.). Direito, governança e novas tecnologias II. Florianópolis: CONPEDI, 2016, p. 77-96.

SANTA CATARINA (Estado). Tribunal de Justiça. Terceira Câmara de Direito Civil. Apelação Cível n. 0000447-46.2016.8.24.0175, relator Des. Saul Steil, julgado em 06 de fevereiro de 2018. 
. Sexta Câmara de Direito Civil. Apelação Cível 0000412-86.2016.8.24.0175, relator: Des. André Luiz Dacol, julgado em 27 de março de 2018.

SCHREIBER, Anderson (Coord.). Direito e Mídia. São Paulo: Atlas, 2013

SOARES, Sávio de Aguiar. Direito Autoral Digital. Belo Horizonte: Editora D’Placido, 2015.

WAGNER, Flávio Rech; CANABARRO, Diego Rafael. A Governança da Internet: definição, desafios e perspectivas. In: PIMENTA, Marcelo Soares; CANABARRO, Diego Rafael (Org.). Governança digital. Porto Alegre: Editora da UFRGS, 2014.

YOUTUBE (AUSTRALIA). Youtube Terms of Service. Disponível em: <https://www.youtube.com/static?template=terms\&gl=AU $>$. Acesso em 03 de set. 2018.

(ÁFRICA DO SUL). Youtube Terms of Service. Disponível em: < <https://www.youtube.com/static?gl=SA\&template=terms $>$. Acesso em 03 de set. 2018.

(ARGENTINA) Términos Y Condiciones del Servicio - Youtube. Disponível em: $<$ https://www.youtube.com/static?template=terms\&hl=es\&gl=AR $>$. Acesso em 03 de set. 2018 .

(BÉLGICA). Youtube Terms of Service. Disponível em: < <https://www.youtube.com/static?gl=NL\&template=terms $>$. Acesso em 03 de set. 2018.

(BRASIL). Termos de Uso. Disponível em: <https://www.youtube.com/static?gl=BR\&template=terms\&hl=pt $>$. Acesso em 03 de set. 2018 .

(CANADA). Youtube Terms of Service. Disponível em: <https://www.youtube.com/static?gl=CA\&template=terms $>$. Acesso em 03 de set. 2018.

(ESPANHA). Términos Y Condiciones del Servicio - Youtube. Disponível em: $<$ https://www.youtube.com/static?template=terms\&hl=es\&gl=ES $>$. Acesso em 03 de set. 2018.

(FRANÇA). Conditions d'utilisation - Youtube. Disponível em: <https://www.youtube.com/static?template=terms\&gl=FR $>$. Acesso em 03 de set. 2018.

(MÉXICO). Términos Y Condiciones del Servicio - Youtube. Disponível em: <https://www.youtube.com/static?gl=MX\&template=terms $>$. Acesso em 03 de set. 2018.

(PANAMÁ). Términos Y Condiciones del Servicio - Youtube. Disponível em: <https://www.youtube.com/static?gl=PN\&template=terms $>$. Acesso em 03 de set. 2018.

(REINO UNIDO). Youtube Terms of Service. Disponível em: <https://www.youtube.com/static?gl=GB\&template=terms $>$. Acesso em 03 de set. 2018.

(URUGUAI). Términos Y Condiciones del Servicio - Youtube. Disponível em: <https://www.youtube.com/static?gl=UY\&template=terms $>$. Acesso em 03 de set. 2018. 